\title{
O SOLO NO ENSINO DE CIÊNCIAS NO NÍVEL FUNDAMENTAL
}

\author{
Soil in science teaching at the Elementary School
}

Marcelo Ricardo de Limal

\begin{abstract}
Resumo: O solo é um componente dos ambientes naturais e antropizados. Apesar de sua importância, este conteúdo usualmente não é abordado com a devida qualidade no Nível Fundamental. Este artigo visa abordar os problemas do ensino de solos no nível fundamental, e propor alternativas para melhorar essa situação. E discutido o papel das universidades neste processo, especialmente na melhoria da formação dos professores do Ensino Fundamental. Também são discutidas outras estratégias, como a realização de cursos, publicaçôes, experimentos, exposições didáticas e uso da internet.
\end{abstract}

Palavras-chave: ensino de solos. Ensino Fundamental. ensino de Ciências.

Abstract: Soil is a component of natural and anthropogenic environments. Despite of its importance, the subject of soil is not usually taught in depth in the elementary school. This paper seeks to show the problems in teaching soil at the elementary school as well as to suggest alternatives to reduce these problems. The role of universities in this process is discussed, emphasizing the aspects related to graduate courses. Also the use of other strategies is discussed like: short courses, didactic books, experiments, exhibitions, and the use of internet.

Keywords: soil teaching. elementary School. Science teaching.

\section{Importância do ensino de solos no nível fundamental}

O solo é um dos componentes dos sistemas terrestres naturais ou antropizados. Devido à sua influência sobre os ambientes e as sociedades é, evidentemente, um dos recursos naturais essenciais (RUELLAN, 1988, p. 70). Segundo Reichardt (1988, p. 75), é necessário se estudar o solo, pois este é útil para que o ser humano produza alimentos e fibras, conserve os ecossistemas e aqüíferos e construa estradas, edifícios e cidades.

Como recurso natural dinâmico, o solo é passível de ser degradado em função do uso inadequado pelo ser humano, acarretando interferências negativas no equilíbrio ambiental e diminuindo drasticamente a qualidade de vida nos ecossistemas, principalmente nos sistemas agrícolas e urbanos. A degradação do solo é observada por meio de: redução da fertilidade natural e do conteúdo de matéria orgânica; erosão hídrica e eólica; compactação; contaminação por resíduos urbanos e industriais; alteração para obras civis (cortes e aterros); decapeamento para fins de exploração mineral; e a desertificação e arenização. Neste contexto, existe o desafio de contribuir para que a população adquira consciência do solo como parte do ambiente, e que o mesmo se encontra ameaçado (FONTES e MUGGLER, 1999, p. 833).

O estudo científico do solo, a aquisição e a disseminação de informações do papel que o mesmo exerce e sua importância na vida do ser humano são condições que auxiliam a

${ }^{1}$ Professor Doutor do Departamento de Solos e Engenharia Agrícola da Universidade Federal do Paraná (UFPR). Rua dos Funcionários, 1540,80035-050,Curitiba (PR).E-mail:mrlima@ufpr.br 
Lima, M. R.

sua proteção e conservação. No entanto, a significância e importância do solo como parte do ambiente é freqüentemente despercebida e subestimada (FONTES e MUGGLER, 1999, p. 833). Obviamente, a mera informação sobre o solo não permitirá que ele seja conservado, pois a degradação dos solos e dos ambientes naturais está relacionada a uma série de aspectos econômicos, políticos e culturais.

Ainda assim, uma das contribuições para colocar estas preocupações no cotidiano da comunidade seria por meio da educação, promovendo a manifestação de uma consciência em relação ao solo, revisando e (re)construindo valores e atitudes (MUGGLER et al., 2004). A melhoria da qualidade do ensino de solos no Nível Fundamental poderia aumentar a consciência ambiental dos estudantes em relação a este recurso natural, o que não resolve o problema da degradação, mas seria mais uma contribuição para a reversão deste processo.

\title{
fundamental \\ O conteúdo de solos nos Parâmetros Curriculares Nacionais do nível
}

O solo é um meio complexo, no qual coexistem três fases diferenciadas (sólida, líquida e gasosa), entre as quais existem múltiplas interações e processos físico-químicos e biológicos (DOMINGUEZ et al., 2005). A complexidade deste tema pode representar um desafio para os professores do Ensino Fundamental, dada a dificuldade de compreensão deste meio heterogêneo e singular, especialmente no primeiro e segundo ciclos. O estudo do solo, ou seja, a pedologia, é um tema que apresenta natureza multidisciplinar, utilizando conhecimentos da geologia, da física, da química, da biologia, da hidrologia, da climatologia etc. (DOMINGUEZ et al., 2005). Porém, Falconi (2004) destaca que os professores avaliam que a limitação em transmitir e ensinar o conteúdo solo pode não ser resultado da complexidade do assunto, mas da formação do docente, acentuada pela dificuldade em entender o conteúdo expresso nos livros didáticos.

No ensino fundamental, conforme destacam Gonzales e Barros (2000, p. 41):

\begin{abstract}
O conteúdo de pedologia começa a ser trabalhado a partir das séries iniciais, ou seja, pela primeira fase do Ciclo Básico de Alfabetização, tanto sob o enfoque geológico, quanto edafológico. Desta forma, o trabalho deve ser feito interrelacionado, para que a criança assimile os conteúdos pedológicos não desvinculados do conhecimento historicamente construído, mas que este aprenda mais que uma leitura de palavras; uma leitura de vida, da sociedade em que está inserida e seu papel dentro dela.
\end{abstract}

Nos Parâmetros Curriculares Nacionais (PCN) do primeiro e segundo ciclos do Ensino Fundamental, o solo é abordado principalmente no contexto das ciências naturais (BRASIL, 1997). O solo também poderia ser abordado como um conteúdo do tema transversal "meio ambiente" em diversas matérias, em momentos específicos.

No primeiro ciclo do Ensino Fundamental, a orientação dos PCN da área de ciências naturais é uma abordagem introdutória do tema solo. Neste ciclo, espera-se que o aluno adquira a capacidade de "observar, registrar e comunicar algumas semelhanças e diferenças entre diversos ambientes, identificando a presença comum de água, seres vivos, luz, calor, solo, e características específicas dos ambientes" (BRASIL, 1997, p. 46). Neste primeiro ciclo, o solo estará inserido dentro do bloco temático "ambiente", no qual segundo os PCN elaborados pela Secretaria Nacional de Ensino Fundamental - SNEF (BRASIL, 1997, p. 47): 
Os conteúdos pretendem uma primeira aproximação da noção de ambiente como resultado das interaçôes entre seus componentes - seres vivos, ar, água, solo, luz e calor - e da compreensão de que, embora constituídos pelos mesmos elementos, os diversos ambientes diferenciam-se pelos tipos de seres vivos, pela disponibilidade dos demais componentes e pelo modo como se dá a presença do ser humano.

Nesta fase, espera-se apenas um primeiro contato do aluno com o solo, mas que deve ser planejado de forma a deixá-lo predisposto ao segundo ciclo do Ensino Fundamental, quando este tema ganha maior destaque.

No segundo ciclo, dentre os objetivos de ciências naturais, espera-se que o aluno possa "identificar e compreender as relaçōes entre solo, água e seres vivos nos fenômenos de escoamento de água, erosão e fertilidade dos solos, nos ambientes rural e urbano", e ainda "caracterizar causas e conseqüências da poluição da água, do ar e do solo" (BRASIL, 1997, p. 57-58). Grande parte do bloco temático "ambiente" é dedicada à discussão de aspectos diretamente relacionados ao solo, como características morfológicas, fertilidade, erosão, textura, matéria orgânica e decomposição, água no solo etc. Também no bloco temático "recursos tecnológicos", o solo volta a ser destaque nos tópicos: água, lixo, solo e saneamento básico, solo e atividades humanas e poluição.

Principalmente no segundo ciclo do Ensino Fundamental, deve haver instrumental didático e capacitação dos professores, que irão introduzir os alunos ao estudo do solo.

No terceiro ciclo do Ensino Fundamental, segundo os PCN (BRASIL, 1998, p. 71):

É possível a retomada ou introdução dos estudos sobre os solos já apontados no segundo ciclo, onde se enfoca a possibilidade dos alunos estudarem a composição, as condições de fertilidade e erosão ou preservação de solos de diferentes origens. No terceiro ciclo, os estudos das características dos solos estão voltados à compreensão da sua profunda integração com o regime de chuvas, com a formação do relevo e da vegetação e com as decorrências da ocupação humana nos biomas brasileiros.

Por sua vez, no quarto ciclo do Ensino Fundamental, nos PCN (BRASIL, 1998, p. 110):

Ao discutir o solo e as atividades agrícolas, retomam-se os estudos já propostos para o segundo ciclo, com maior profundidade e abrangência. Agora, a fertilização, a irrigação ou a drenagem podem ser trabalhados considerando-se seus aspectos físico-químicos, associando-se suas características aos processos de correção e aos ciclos naturais. (...) Os processos de degradação dos ambientes por queimadas, desmatamento e conseqüente erosão do solo, ao lado de medidas de contenção e correção, também podem ser retomados, buscando-se uma abordagem mais ampla do que no segundo ciclo, por meio de suas relações com os ciclos dos materiais. (...) Ao abordar a degradação de ambientes em áreas urbanas, retomam-se os estudos sobre poluição do ar, da água e do solo.

Percebe-se claramente que, enquanto no segundo ciclo há a preocupação em se "apresentar" o solo ao estudante, no terceiro e quarto ciclos os PCN tendem a relacionar o solo com outros processos ou fenômenos estudados, de modo a integrar os conhecimentos adquiridos, e aprofundar o tema sob enfoque interdisciplinar.

No entanto, deve-se considerar que, segundo Sposito (1999, p. 34), os PCN não são considerados unanimemente adequados, em função de sua elaboração não ter sido plural, e 
Lima, M. R.

ainda por apresentar dificuldades, imprecisões e até mesmo incoerências. Esta preocupação é expressa por Pontuschka (1999, p. 16), ao afirmar que:

Os PCN destinam-se à minoria dos professores bem formados, que com maior ou menor intensidade já conhecem a bibliografia mais atualizada e acompanham a trajetória percorrida pela ciência (...) O texto ainda é teórico demais para o professor que ainda utiliza o livro didático como sua única ou principal bibliografia. Desse modo, ao lado dos PCN, muitas outras ações precisam ser efetivadas para que o público-alvo possa elevar a qualidade de seu trabalho de acordo com os objetivos previstos pelo MEC.

Esta afirmação mostra a necessidade de se programarem ações que possam traduzir a linguagem dos PCN para a realidade dos professores em sala de aula, de modo a se inserir de fato o conteúdo solos no cotidiano da sala de aula.

\section{O ensino de solo no nível fundamental}

O professor do Ensino Fundamental freqüentemente tem dificuldade em ver o solo como um importante elemento da paisagem, e o ensino de solos, quando existe, torna-se mecânico e sem utilidade para o aluno (RODRIGUES et al., 2003; ABREU, 2000), com base principalmente em aulas expositivas (FALCONI, 2004).

Neste nível de ensino, de modo geral, os materiais instrucionais impressos são os recursos de ensino mais utilizados pelos professores, destacando-se os livros didáticos e as apostilas, que são produzidos em larga escala e sem teste científico que garanta a sua validade, atualidade e eficiência (MARTINS, 1997, p. 8). Ao se comparar o proposto nos PCN para o tema solos, com a realidade dos livros didáticos, encontra-se uma diferença significativa, quer seja pela ausência, incorreção ou inadequação das informações existentes (AMORIM e MOREAU, 2003). De modo geral, os livros didáticos traduzem pontos de vista que são descritos por Rebollo et al. (2005) como estáticos, como a visão agrícola ou a visão geológica do solo, freqüentemente ignorando abordagens interdisciplinares ou ecológicas. Muitas vezes, os estudantes das áreas urbanas não percebem que o solo apresenta importância, pois, segundo Amorim e Moreau (2003), este conteúdo nos livros didáticos é contextualizado para a atividade agrícola, não se aproximando da realidade da maioria destes alunos.

Esses problemas não se restringem à questão do solo, pois, segundo Megid Neto e Fracalanza (2003, p. 154), o livro didático não corresponde a uma versão fiel das diretrizes e programas curriculares oficiais, nem a uma versão fiel do conhecimento científico", além de "introduzir ou reforçar equívocos, estereótipos e mitificações com respeito às concepções de ciência".

A título de exemplo, em um dos livros recomendados para a área de ciências, no Programa Nacional do Livro Didático - PNLD 2002, a SNEF (BRASIL, 2001) faz a seguinte avaliação:

Em particular, o capítulo que trata sobre "solos" apresenta algumas informações imprecisas, exigindo uma intervenção significativa do professor. Há uma confusão entre porosidade e permeabilidade que deve ser revista. O livro afirma que solos arenosos são muito permeáveis por apresentarem poros grandes $\mathrm{e}$ numerosos e a argila, por sua vez, apresenta poros minúsculos e em número reduzido, sendo pouco permeável. A relação adequada seria a inversa: o 
tamanho reduzido causa a presença de maior número dos poros e, portanto, maior retenção de água. $O$ texto apresenta também uma tabela com solos classificados segundo parâmetros diferentes, como textura e composição, o que leva à impossibilidade de comparação entre os tipos. Nessa tabela, surgem algumas definições redundantes e confusas, como, por exemplo, a afirmação de que solos arenosos têm bastante areia (70\%); solos argilosos, bastante argila (30\%) e solos humíferos, bastante humo (10\%). Como os valores percentuais apresentados não são discutidos, a diferença entre $70 \%$ e $10 \%$ é significativa o suficiente para levar o aluno a se questionar sobre o que significa "bastante areia" ou "bastante humo".

Segundo Curvello et al. (1995, p. 2174), o ensino de solos no Ensino Fundamental, de modo geral, é particularmente mecânico, por meio da transmissão de conhecimentos, os quais freqüentemente não são relacionados às necessidades e anseios dos estudantes. Nos livros didáticos, estes autores destacam que o estudo do solo é tratado por exercícios que desenvolvem apenas habilidades de memorização dos conteúdos (preenchimento de lacunas, respostas diretas, palavras cruzadas, questões de múltipla escolha, etc.), impedindo o ato de raciocinar, imaginar e criar. No entanto, para que a aprendizagem realmente aconteça, precisa ser significativa para o aprendiz, isto é, necessita envolvê-lo como pessoa, como um todo (idéias, sentimentos, cultura, sociedade) (ABREU e MASETTO, 1990, p. 9). O processo de aprendizagem de solos no Ensino Fundamental deveria conter experiências concretas que levassem o estudante à construção gradativa do conhecimento, a partir de um fazer científico, levando em conta a vinculação da ciência ao seu significado político, social e cultural (CURVELlO e SANTOS, 1993, p. 192). Segundo Dominguez e Negrin (1998), para transmitir o valor do recurso natural solo é necessário que o aluno tenha uma experiência pessoal com o mesmo, não havendo outro caminho para ensinar a "vida" dinâmica do solo e a necessidade de sua conservação.

Segundo Diniz et al. (2005), a popularização do conhecimento pedológico também passa por uma abordagem que considera o conhecimento sobre solos das comunidades locais. Segundo Silva (1999):

(...) as crianças possuem conceitos próprios sobre fenômenos da natureza, entre eles os relacionados à ciência do solo. Elas formam e expressam esses conceitos de várias maneiras, podendo seguir a sua vivência do dia-a-dia ou serem induzidos pelo conceito dado na escola. (...) Percebe-se que elas podem entender um conceito de vários modos, o que é diferente de não ter aprendido.

O solo também pode ser o tema gerador de trabalhos interdisciplinares, que possibilitam ao professor do ciclo básico de alfabetização desenvolver muitas áreas do conhecimento, sem que se priorize este tema, mas articulando-o com os demais. Esta proposta foi testada com resultados satisfatórios em algumas escolas do Paraná, Rio Grande do Sul, São Paulo, Pernambuco e Amapá (GONZALES e BARROS, 2000, p. 43; NICOLA et al., 2000, p. 81). Neste trabalho, o procedimento técnico adotado foi

(...) a abordagem morfológica do solo, ou seja, começando o estudo dos solos pela descrição de campo, da anatomia (morfologia), descobrem-se as propriedades dos solos, suas fertilidades, seus comportamentos face às plantas, às técnicas agrícolas e aos manejos. É em função dos dados morfológicos que serão abordados os conhecimentos 
Lima, M. R.

(biológicos, químicos, físicos, mecânicos) relativos aos solos, às relações solo-planta, ao manejo e à exploração, isto é, toda gama de possíveis interpretações.

A articulação entre o solo e a questão ambiental foi a premissa do trabalho que Campos et al. (1999, p. 830) desenvolveram com estudantes do Ensino Fundamental. A partir de noticiário de televisão que falava do problema das enchentes, foi construído um processo de discussão sobre a poluição do solo, água e ar, erosão e lixo, no qual os próprios estudantes acabaram se envolvendo em atividades comunitárias, visando minimizar os impactos destes problemas.

Outro problema relacionado ao ensino de solos no nível fundamental é o fato deste conteúdo ser constantemente atualizado, em virtude da evolução da pedologia no Brasil nas últimas décadas. A classificação de solos utilizada atualmente no País, por exemplo, permanece ignorada pela maioria dos professores e estudantes do Ensino Fundamental. Freqüentemente se encontram nos livros didáticos termos obsoletos ou "importados" para classificar o solo, tais como zonal, azonal, massapé, terra roxa, hidromórficos, löess, dentre outros (AMORIM e MOREAU, 2003). Raramente há citação nos livros didáticos, por exemplo, aos latossolos, que são os principais solos no Brasil em termos de área geográfica e importância econômica.

Parece existir, também, um descompasso entre o desejo dos alunos e o que os professores acham que estes desejam estudar. Estudos realizados por Oliveira et al. (2001, p. 305), Rieder (1996, p. 288) e Rodrigues et al. (2003) mostram que, de modo geral, os estudantes do Ensino Fundamental têm grande interesse em estudar solos. No entanto, estes estudos apontam que há uma satisfação baixa com o nível do conteúdo, ou um reduzido interesse dos professores em lecionar este tema. Estes resultados são o reflexo de um conjunto de fatores educacionais, que não podem ser analisados isoladamente, mas permitem visualizar uma dicotomia entre os anseios dos estudantes e a realidade educacional.

Mesmo dentro da própria ciência do solo, o ensino de solos não tem o destaque necessário, pois, ao analisar os anais de todos os Congressos Brasileiros de Ciência do Solo, desde 1949 até 1989, Beck e Spier (1991, p. 155) encontraram apenas 11 trabalhos relacionados a este tema, os quais, "embora valiosos individualmente, não apresentavam continuidade, articulação ou integração entre si, revelando ausência de diretrizes, acompanhamento, e (...) pouca valorização do tema no âmbito dos congressos". Apesar da realização de seminários nacionais sobre ensino de solos na década de 1990, o tema ainda é restrito a uma pequena porção da sociedade e, principalmente, voltado ao Ensino Superior (DINIZ et al., 2005).

\section{A contribuição das Instituições de Ensino Superior na melhoria do ensino de solos}

As Instituições de Ensino Superior (IES) brasileiras, e em especial as universidades, podem auxiliar os professores do Ensino Fundamental na resolução dos problemas relatados no capítulo anterior, por meio de suas funções de ensino, pesquisa, extensão. Porém, embora as IES brasileiras tenham uma grande experiência na pesquisa básica e aplicada na área de solos, a discussão do ensino, e o desenvolvimento de tecnologia educacional sobre este tema não têm tido espaço adequado e privilegiado. 
O fato de os professores estarem reproduzindo os conteúdos de solos inadequados, defasados ou incorretos existentes nos livros didáticos (AMORIM e MOREAU, 2003), é, em parte, conseqüência da própria formação que estes receberam nos cursos de licenciatura. Esses professores não desenvolveram habilidades, bem como não têm tempo ou oportunidade, para buscar outras fontes de informação além dos livros didáticos ou para avaliar a incompatibilidade dos mesmos na área de solos.

Segundo Pereira (1998, p. 104), de modo geral, a representação que os professores dos cursos de licenciatura têm do ensino é a idéia da transmissão de conhecimentos, reforçada por um modelo de currículo que se estrutura e se baseia em "o que ensinar" (disciplinas de conteúdo) e em "como ensinar" (disciplinas pedagógicas). Segundo Cunha (2000, p. 45), na universidade "há um imaginário (...) que concebe a docência como atividade científica, em que basta o domínio do conhecimento específico e o instrumental para a produção de novas informaçôes para que se cumpram seus objetivos". Enquanto os professores de Ensino Fundamental têm, com a licenciatura, uma formação didático-pedagógica, aos professores do Ensino Superior isso não é exigido (FERREIRA, 1988, p. 190). É de se esperar, portanto, que os professores das IES, quando lecionam o conteúdo solos, o fazem de maneira semelhante para os estudantes de bacharelado e licenciatura, sem distinguir as especificidades de cada formação.

Portanto, a principal contribuição das IES na melhoria do ensino de solos, está justamente, em incluir ou qualificar a formação pedológica dos futuros professores, observando suas necessidades e especificidades, aspecto que demanda uma nova visão deste tema por parte dos professores universitários.

Por outro lado, depois de formados, não se pode esperar que os professores de Ensino Fundamental possam acompanhar a evolução do conhecimento pedológico, sem que se pense em programas de educação continuada destes profissionais, para propiciar a atualização dos procedimentos didáticos e dos conteúdos de suas disciplinas. $\mathrm{Ou}$ ainda, conforme afirma Pontuschka (1999, p. 16), a formação permanente do professor, eliminando a dicotomia entre formação inicial e formação continuada. Neste sentido, além de melhorar a qualificação dos profissionais que a licenciatura está formando, as IES também podem contribuir no sentido de propor atividades (projetos, programas, eventos, cursos ou publicações) que possam auxiliar na melhoria da capacitação do professores para compreender e ensinar o tema solos, bem como ajudar a desenvolver recursos didáticos sobre solos para o Ensino Fundamental.

No intuito de promover a educação continuada dos educadores, algumas IES realizam cursos e eventos (LIMA et al., 2002a; MUGGLER et al., 2004), visando à troca de experiências com professores do Ensino Fundamental, e discutindo o solo como um integrante do ambiente natural, o qual é importante tanto no meio rural como no urbano. Estas atividades necessitam ser dinâmicas, aproveitando as experiências dos participantes, levando novos conhecimentos e exercitando ações em campo (onde efetivamente está o solo). No entanto estas iniciativas isoladas têm de ser ampliadas para poder abranger um contingente maior de educadores, inclusive por meio de cursos não presenciais.

Considerando as limitaçôes de muitos livros didáticos, outro papel das IES é contribuir para a produção de material que possa ser utilizado, por professores ou alunos do 
Lima, M. R.

Ensino Fundamental. Este auxiliar deve ser claro e acessível, tendo o tema "solo" como um conteúdo transversal e estabelecendo sua relação com outras matérias, além das ciências naturais. É uma oportunidade de desenvolver material que seja adequado à realidade dos solos brasileiros, correto tecnicamente e compatível com os PCN. Naturalmente que, para desenvolver este trabalho, é necessária uma articulação entre os profissionais da pedologia e das licenciaturas. Este tipo de iniciativa, além de atingir professores e alunos do Ensino Fundamental, também pode servir de estímulo à reformulação dos livros didáticos existentes. A elaboração de livros ou cartilhas, com conceitos básicos em ciência do solo, para professores ou alunos do Ensino Fundamental é uma estratégia que está sendo desenvolvida em algumas IES (CURVELLO et al., 1995; MUGGLER e CARDOSO, 1999; LIMA et al., 2004), tendo como embasamento a construção do conhecimento científico e o construtivismo.

Também podem contribuir neste sentido o desenvolvimento de protocolos de experiências simples (BRECHBUEHLER e CARDOSO, 1995; STEFANI, 1996; LENZI e FÁVERO, 2000; LIMA et al., 2002b; CARPENTER, 2003; FALCONI, 2004) para auxiliar o ensino de atributos do solo, estimulando os alunos a refletirem sobre os resultados obtidos e as interaçôes com outros temas.

Uma das contribuições que as IES podem oferecer aos professores do Ensino Fundamental é a implantação ou incentivo à organização de acervos referenciais de monólitos de solos, representativos de cada região, os quais serviriam como instrumento para demonstração ou experimentação de estudantes de Ensino Fundamental. Uma exposição de solos proporciona aos seus usuários uma experiência sensorial importante para a elaboração de concepções de feições morfológicas. Além disto, o visitante pode associar a distribuição de solos com o material de origem, relevo e clima, estabelecendo relaçóes de causa e efeito, considerando os fatores e processos de formação dos solos. Também podem ser visualizados outros atributos do solo, como profundidade, seqüência de horizontes, pedregosidade, cor etc. (DALMOLIN et al., 1996, p. 277).

A finalidade de um monólito de solo não é substituir o exame e estudo do solo na paisagem natural onde ocorre e, sim, complementá-lo, possibilitando o estudo e a comparação de diferentes solos. No campo, essa comparação é dificultada, uma vez que os vários tipos de solos ocupam diferentes lugares na paisagem e, freqüentemente, em locais de acesso difícil ou perigoso, especialmente para os estudantes que freqüentam o Ensino Fundamental.

No entanto, a principal limitação da coleção de monólitos de solo é o aspecto estático deste tipo de exposição, que não permite a interação ativa do usuário. Portanto, estas exposiçōes podem ser complementadas por atividades dinâmicas, procurando instigar os visitantes (professores e alunos de escolas de nível fundamental) a participar das mesmas, incluindo outros recursos, como maquetes e experiências. Em exposições didáticas podem ser exercitadas a observação e a experimentação, que são duas orientações didáticas importantes, destacadas nos PCN do Ensino Fundamental (BRASIL, 1997, p. 79-80; BRASIL, 1998, p. 121-122).

As exposições didáticas de solos, que também podem incluir minerais e rochas, têm sido desenvolvidas em algumas IES (BRECHBUEHLER e CARDOSO, 1995; DALMOLIN et al., 1996; LIMA et al., 2002a; SILVA et al., 2004; DINIZ et al., 2005). Segundo Brechbuehler e Cardoso (1995), "o museu de solos é um instrumento de rompimento com a 
alienação vivida por grande parcela da sociedade que, por não ter acesso às informações científicas e tecnológicas, na maioria das vezes, não se importa com os problemas ambientais".

Existem diversos meios de difusão da informação gerada pelas diferentes atividades descritas, muitos deles já amplamente utilizados na educação ambiental (televisão, internet, vídeo etc.), mas ainda incipientes quando se trata de um enfoque pedológico. $\mathrm{O}$ uso da internet traz múltiplas possibilidades a serem exploradas (FONTES e MUGGLER, 1999, p. 833), sendo um instrumento de divulgação científica e tecnológica, utilizado por estudantes que buscam informações, especialmente para complementar estudos, trabalhos escolares, feiras de ciências, e outros. No terceiro e quarto ciclos do Ensino Fundamental os PCN consideram a internet um auxiliar passível de utilização (BRASIL, 1998, p. 130), e as IES poderiam desenvolver recursos como CD-ROM ou sites com informações sobre o solo, como os exemplos de instituições como Empraba-CNPS, IBGE e UFPR (www.escola.agrarias.ufpr.br).

Estas açõos, que podem mesclar os conhecimentos de diferentes áreas, também permitem o exercício da interdisciplinaridade, muito útil à formação dos professores e à mudança de comportamento frente às suas atividades de ensino. Além disto, estas práticas também permitem ao professor universitário repensar a sua própria prática na formação de futuros docentes do Ensino Fundamental.

\section{Considerações finais}

Apesar da importância do solo para o ser humano, o ensino deste tema na educação fundamental pode ser considerado de qualidade inferior à desejada, devido a um conjunto de fatores educacionais, sociais e econômicos. O conteúdo solos, embora abordado nos PCN e nos currículos escolares, apresenta problemas em sua implantação, por causa de falhas nos livros didáticos e na formação básica e continuada dos professores.

A principal contribuição das Instituições de Ensino Superior (IES), no sentido de auxiliar os professores do Ensino Fundamental a melhorar o ensino de solos, é repensar e redefinir o direcionamento no qual estão sendo formados os futuros professores, que irão atuar no ensino de solos na educação fundamental.

As instituiçôes de Ensino Superior também podem contribuir, por meio de ações como cursos e eventos de educação continuada, elaboração de publicações, desenvolvimento de experiências, organização de exposições didáticas, e disponibilizando informações por meio da internet, dentre outras atividades.

\section{Referências}

ABREU, Â. O ensino de solos nos niveis fundamental e médio: o caso da Escola Estadual Cidade dos Meninos. Belo Horizonte, 2000. Monografia (Licenciatura Plena em Geografia) - Instituto de Geociências, Departamento de Geografia, Universidade Federal de Minas Gerais.

ABREU, M. C.; MASETTO, M. T. O professor universitário em aula: prática e princípios teóricos. 8. ed. São Paulo: MG Editores Associados, 1990.

AMORIM, R. R.; MOREAU, A. M. S. S. Avaliação do conteúdo da ciência do solo em livros didáticos de geografia do Ensino Médio. In: SIMPÓSIO BRASILEIRO DE GEOGRAFIA 
Lima, M. R.

FÍSICA APLICADA, 10., 2003, Rio de Janeiro. GEO-UERJ - Revista do Departamento de Geografia, n. especial, p. 74-81, 2003.

Disponível em http://geografia.igeo.uerj.br/xsbgfa/cdrom/eixo1/1.1/119/119.htm

BECK, F. L.; SPIER, M. O tema ensino de solo nos anais dos congressos brasileiros de ciência do solo e na Revista Brasileira de Ciência do Solo. In: CONGRESSO BRASILEIRO DE CIÊNCIA DO SOLO, 23., 1991, Porto Alegre. Programa e Resumos. Porto Alegre: Sociedade Brasileira de Ciência do Solo, 1991. p. 155.

BRASIL. Secretaria de Educação Fundamental. Parâmetros Curriculares Nacionais: ciências naturais. Brasília: MEC/SEF, 1997.

- Secretaria de Educação Fundamental. Parâmetros Curriculares Nacionais: terceiro e quarto ciclos: ciências naturais. Brasília: MEC/SEF, 1998.

. Secretaria de Educação Fundamental. Guia de livros didáticos - PNLD 2002. Brasília: MEC/SEF, 2001.

BRECHBUEHLER, A. J. M. M.; CARDOSO, I. M. Museu Alexis Dorofeef - minerais, rochas e solos. Uma experiência de ensino informal. In: CONGRESSO BRASILEIRO DE CIÊNCIA DO SOLO, 25., 1995, Viçosa. Resumos Expandidos. Viçosa: SBCS, UFV, 1995. p. 2204-2205.

CAMPOS, C. E. B. et al. Em defesa da vida: reflexão sobre o uso inadequado dos recursos naturais. In: CONGRESO LATINOAMERICANO DE LA CIENCIA DEL SUELO, 14., 1999, Pucón (Chile). Resumenes. Temuco: Universidad de la Frontera, 1999. p. 830.

CARPENTER, D. D. Hands-on experiments for teaching children about erosion, watershed management and water resources. In: WORLD WATER AND ENVIRONMENT RESOURCES CONGRESS, 2003. Philadelphia. Proceedings... Philadelphia: American Society of Civil Engeneers, 2003. p. 34-43.

CUNHA, M. I. Ensino como mediação da formação do professor universitário. In: MOROSINI, M. C. (org.) Professor do ensino superior: identidade, docência e formação. Brasília: Inep, 2000. 80 p.

CURVELLO, M. A.; SANTOS, G. A. Adequação de conceitos básicos em ciência do solo para aplicação na escola de $1^{\circ}$ grau. In: CONGRESSO BRASILEIRO DE CIÊNCIA DO SOLO, 24., 2003. Goiânia, 1993. Resumos. Goiânia: SBCS, 1993, v. 3, p. 191-192.

. et al. Elaboração de um livro de conceitos básicos em ciência do solo para o ensino de primeiro grau. In: CONGRESSO BRASILEIRO DE CIÊNCIA DO SOLO, 25., 1995. Viçosa. Resumos Expandidos. Viçosa: SBCS, UFV, 1995. p. 2174-2175.

DALMOLIN, R. S. D. et al. Utilização do museu de solos como instrumento didático. In: SIMPÓSIO BRASILEIRO SOBRE ENSINO DE SOLOS, 2., 1995. Documento Final. Santa Maria: SBCS, UFSM, 1996. p. 277-278.

DINIZ, A. A.; BATISTA, R. B.; SANTOS, R. F. Popularização da taxonomia do solo: vocabulário mínimo e aspectos sócio-econômicos no contexto do Ensino Fundamental, em São Miguel, Esperança (PB). Revista Brasileira de Ciência do Solo, Viçosa, v. 29, p. 309-316, 2005. 
DOMINGUEZ, J.; NEGRIN, M. A. Soil science education: mechanistic vs. holistic paradigm. In: WORLD CONGRESS OF SOIL SCIENCE, 16., 1998. Montpellier. Proceedings... Montpellier, International Union of Soil Sciences, 1998. Symposium 44. Disponível em: http://natres.psu.ac.th/Link/SoilCongress/en/symt44.htm

.; RODRIGUEZ, C. M.; NEGRIN, M. A. La educación edafológica entre el transito de la educación secundaria e la universidad. In: CONGRESO INTERNACIONAL SOBRE INVESTIGACIÓN EN LA DIDÁCTICA DE LAS CIENCIAS, 7., 2005. Granada. Enseñanza de las ciencias, Barcelona, n. extra, 2005.

Disponível em: http://www.blues.uab.es/ -sice23/congres2005/htm/aa.htm

FALCONI, S. Produção de material didático para o ensino de solos. Rio Claro, 2004. Dissertação (Mestrado em Geografia) - Instituto de Geociências e Ciências Exatas, Universidade Estadual Paulista.

FERREIRA, M. G. V. X. Ensino de solos: uma visão global. In: MONIZ, A. C. et al, (eds.). A responsabilidade social da ciência do solo. Campinas: Sociedade Brasileira de Ciência do Solo, 1988. p.187-191.

FONTES, L. E. F.; MUGGLER, C. C. Educação não formal em solos e o meio ambiente: desafios na virada do milênio. In: CONGRESO LATINOAMERICANO DE LA CIENCIA DEL SUELO, 14., 1999, Pucón (Chile). Resumenes. Temuco: Universidad de la Frontera, 1999. p. 833.

GONZALES, S. L. M.; BARROS, O. N. F. O ensino de pedologia no ciclo básico de alfabetização. Geografia, Londrina, v. 9, n. 1, p. 41-49, 2000.

LENZI, E.; FÁVERO, L. O. B. Brincando com as propriedades físicas do solo. Arquivos da APADEC, Maringá, v. 4, n. 1, p. 36-39, 2000.

LIMA, V. C. et al. Projeto solo na escola: o solo como elemento integrador do ambiente no ensino fundamental e médio. Expressa Extensão, Pelotas, v. 7, n. especial, 2002a. CD-ROM.

. et al. Solos para professores do ensino fundamental e médio. 4. aprox. Curitiba: Universidade Federal do Paraná, Departamento de Solos e Engenharia Agrícola, 2004.

LIMA, M. R.; YOSHIOKA, M. H.; MACANHÃO, P. O ensino de solos através do uso de experimentoteca. In: FÓRUM DE ATIVIDADES FORMATIVAS, 1., 2002, Curitiba. Anais..., Curitiba: Universidade Federal do Paraná, Pró-Reitoria de Graduação, 2002b. CDROM.

MARTINS, A. R. Sobre os recursos do ensino. Tecnologia Educacional, Rio de Janeiro, v. 25, n. $134 / 135,1997$, p. 7-11.

MEGID NETO, J.; FRACALANZA, H. O livro didático de ciências: problemas e soluções. Ciência \& Educação, Bauru, v. 9, n. 2, p. 147-157, 2003.

MUGGLER, C. C.; CARDOSO, I. M. Museu de solos como ferramenta de consciência ambiental e desenvolvimento comunitário. In: CONGRESSO BRASILEIRO DE CIÊNCIA DO SOLO, 27, 1999. Brasília. Resumos. Brasília: SBCS, 1999. CD-ROM. 
Lima, M. R.

. et al. C. A. Capacitação de professores do Ensino Fundamental e Médio em conteúdos e métodos em solos e meio ambiente. In: CONGRESSO BRASILEIRO DE EXTENSÃO UNIVERSITÁRIA, 2., 2004. Belo Horizonte. Anais..., Belo Horizonte: Fórum de Pró Reitores de Extensão das Universidades Públicas Brasileiras, 2004. CD-ROM.

NICOLA, S. M. C. et al. Valorização do ensino da ciência do solo nas escolas públicas do município de Ijuí - RS, Brasil. Geografia, Londrina, v. 9, n. 1, p. 81-82, 2000.

OLIVEIRA, C. V.; COSTA, A. D. C.; ABREU, A. C. E. O ensino de solos e os professores do Ensino Fundamental. In: CONGRESSO BRASILEIRO DE CIÊNCIA DO SOLO, 28., 2001. Londrina. Resumos. Londrina: SBCS, 2001. p. 305.

PEREIRA, J. E. D. O que os professores de um curso de licenciatura pensam sobre ensino? Educação em Revista, Belo Horizonte, n. 28, p. 95-105, 1998.

PONTUSCHKA, N. N. Parâmetros curriculares nacionais: tensão entre estado e escola. In: CARLOS, A. F. A.; OLIVEIRA, A. U. (orgs.). Reformas no mundo da educação: parâmetros curriculares e geografia. São Paulo: Contexto, 1999. p. 15-18.

REBOLLO, M.; PRIETO, T.; BRERO, V. Aproximación a la historia y epistemología del concepto de suelo: implicaciones didácticas. In: CONGRESO INTERNACIONAL SOBRE INVESTIGACIÓN EN LA DIDÁCTICA DE LAS CIENCIAS, 7., 2005. Granada. Enseñanza de las ciencias, Barcelona, n. extra, 2005. Disponível em:

http://www.blues.uab.es/ - sice23/congres2005/htm/aa.htm

REICHARDT, K. Por que estudar o solo? In: MONIZ, A. C.; FURLANI, A. M. C.; FURLANI, P. R.; FREITAS, S. S. (eds.). A responsabilidade social da ciência do solo. Campinas: Sociedade Brasileira de Ciência do Solo, 1988. p. 75-78.

RIEDER, A. Nível de interesse por solos e suas fontes de estímulo. In: SIMPÓSIO BRASILEIRO SOBRE ENSINO DE SOLOS, 2., 1995, Santa Maria. Documento Final. Santa Maria: SBCS, UFSM, 1996. p. 288-289.

RODRIGUES, R. et al. Diagnóstico do ensino de solos no nível fundamental em escolas da região metropolitana de Curitiba. In: ENCONTRO DE EXTENSÃO E CULTURA DA UFPR, 2., 2003. Curitiba. Anais..., Curitiba: Universidade Federal do Paraná, Pró-Reitoria de Extensão e Cultura, 2003. CD-ROM.

RUELLAN, A. Pedologia e desenvolvimento: a ciência do solo a serviço do desenvolvimento. In: MONIZ, A. C.; FURLANI, A. M. C.; FURLANI, P. R.; FREITAS, S. S. (eds.) A responsabilidade social da ciência do solo. Campinas: Sociedade Brasileira de Ciência do Solo, 1988. p. 69-74.

SILVA, A. J. N. Conceitos espontâneos de crianças sobre fenômenos relativos à ciência do solo. In: CONGRESSO BRASILEIRO DE CIÊNCIA DO SOLO, 27., 1999, Brasília. Resumos. Brasília: SBCS, 1999. CD-ROM.

SILVA, E. G. et al. Importância da elaboração de materiais didáticos no ensino de solos para a geografia. In: CONGRESSO BRASILEIRO DE GEÓGRAFOS, 6., 2004, Goiânia. Resumos. Goiânia: Associação dos Geógrafos Brasileiros, 2004. CD-ROM. 
SPOSITO, M. E. B. Parâmetros curriculares nacionais para o ensino de geografia: pontos e contrapontos para uma análise. In: CARLOS, A. F. A.; OLIVEIRA, A. U. (orgs.) Reformas no mundo da educação: parâmetros curriculares e geografia. São Paulo: Contexto, 1999. p. 19-35.

STEFANI, A. Estudando o solo: atividades que estimulam a investigação científica. Revista do Professor, Porto Alegre, v. 12, n. 46, p. 25-32, 1996.

Artigo recebido em março de 2005 e selecionado para publicação em agosto de 2005. 